\title{
Androgen Receptor and ETS-Like Protein-1 Expression of Prostate Cancer Correlates with Gleason Score International Society of Urological Pathology 2014/WHO 2016
}

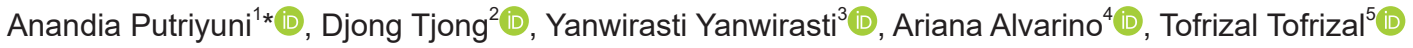 \\ ${ }^{1}$ Department of Biomedical Science, Faculty of Medicine, Andalas University, Padang, Indonesia; ${ }^{2}$ Department of Biology, \\ Faculty of Mathematics and Naturals Sciences, Andalas University, Padang, Indonesia; ${ }^{3}$ Department of Anatomy, Faculty of \\ Medicine, Andalas University, Padang, Indonesia; ${ }^{4}$ Department of Surgery, Division of Urology, Faculty of Medicine, Andalas \\ University, Padang, Indonesia; ${ }^{5}$ Department of Anatomical Pathology, Faculty of Medicine, Andalas University, Padang, \\ Indonesia
}

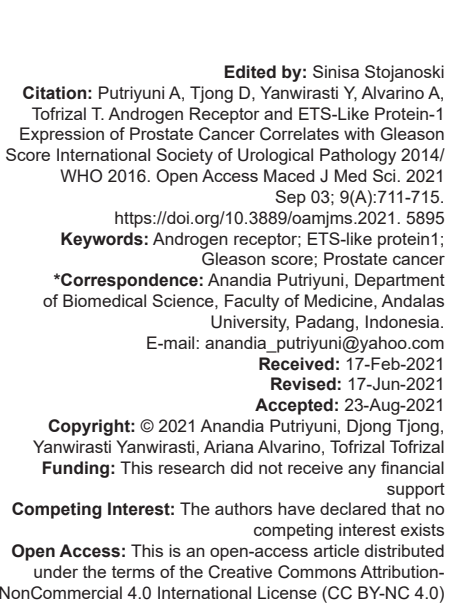

\section{Abstract}

AIM: Prostate cancer is the second most common and the fifth leading cause of death by cancer in men worldwide now. Grading based on Gleason score is a significant prognostic factor of prostate cancer. Androgen receptor (AR) plays important role in the initiation and progression of prostate cancer. AR signaling pathways in prostate cancer can also promote MAPK/ERK signaling pathways which activate ETS-like protein1 (Elk-1).

METHODS: A total of 56 slides and paraffin blocks sampling of prostate cancer by consecutive from Department of Anatomical Pathology in West Sumatera. Hematoxylin and eosin (HE) stained slides were evaluated to review Gleason score, histopathological grading, and WHO grade group based on International Society of Urologica Pathology (ISUP) 2014/WHO 2016. Immunohistochemistry staining of AR and Elk-1 was performed to analyze protein expression

RESULTS: Prostate cancers were found in mean age $70.68 \pm 7.99$ years. The most proportion of prostate cancer was Gleason score $9(44.64 \%)$, histopathological grading poorly differentiated/undifferentiated $(76.78 \%)$, and WHO grade Group $5(48.21 \%)$. The positive expression AR of tumor cells $39(69.64 \%)$ and Elk-1 $34(60.71 \%)$. Statistically, these results showed significant correlations of AR $(p=0.009)$ and Elk-1 $(p=0.012)$ with Gleason score.

CONCLUSIONS: These results showed complex interactions between AR and Elk-1 initiation and progression of prostate cancer. Both variables indicated a significant correlation with Gleason score so that biomarkers prognostic potentially for prostate cancer.

\section{Introduction}

Prostate cancer connotes as adenocarcinoma prostate is the malignant neoplasm [1]. It is currently the second most common cancer in worldwide after lung cancer in males based on GLOBOCAN IARC 2018. It is reported 1.3 million $(7.1 \%)$ new cases, increasing from 2012 (1.1 million). Prostate cancer is the fifth leading cause of death by cancer in males [2], [3]. Cancer Registry of Indonesian Pathologist Association 2014 reported that prostate cancer is the fourth most common from ten males primary tumor in Indonesia. It is found 80 cases in Padang city 2014 that the second most common from ten males primary tumor, increasing from past years [4].

The growth, progression, and metastases of prostate cancer are highly influenced by Androgen receptor (AR) signaling, which is critical signaling for prostate cancer. The AR plays important role in the initiation and progression of prostate cancer, but its mechanism is still unclear. Androgen deprivation therapy (ADT) is the principal therapy for prostate cancer with local and metastases. Over time the most cancer cells show AR signaling pathways activated during ADT which causes resistance [5], [6]. Activation of MAPK/ERK cascade is a primary mitogenic stimulus initiated by non-genomic AR signaling in prostate cancer observed in androgen-sensitive prostate cells. ETS-like protein1 (Elk-1), the transcription factor is a downstream target of MAPK/ERK pathways, which plays role in the progression of cancer. The transcription factor of Elk-1 is involved in various cellular functions such as proliferation, differentiation, invasion, and survival. Exaggerate activation in these pathways which are induced by stimulation or mutation AR and Elk-1 promote growth, survival, and progression of prostate cancer [7], [8], [9].

The prostate cancer grading system according to the Gleason score currently used worldwide was 
introduced by Donald F. Gleason. A new grading system has been proposed by The International Society of Urological Pathology (ISUP) in 2014 and is integrated into the 2016 edition of the WHO classification of Tumor of the Urinary System and Male Genital [10], [11]. Gleason score is one of the conventional clinicopathological parameters and the most important prognostic factor in progression and metastases of prostate cancer [12]. There is no study on AR, Elk-1 expression, and correlation with Gleason score, particularly in West Sumatera, Indonesia.

\section{Materials and Methods}

The observational study used a total of 56 cases of prostate cancer from Department of Anatomical Pathology archieves in West Sumatera. The study was approved by the local research and ethical review committee. Hematoxyline and eosin (HE) stained slides and paraffin blocks were retrieved. Slides of all cases were evaluated to review Gleason score, histopathological grading, and WHO grade group based on ISUP 2014/WHO 2016. Gleason score was grouped into a low grade (Gleason score < 8) and high grade (Gleason score 8-10). Specimens included prostatic chips and prostatectomies. Moreover, representative tissue blocks of all 56 cases were selected for Immunohistochemistry (IHC) examination.

IHC staining has been carried out at the Anatomical Pathology Department of General Hospital Dr. Cipto Mangunkusumo Jakarta. The antibodies were primary mouse monoclonal anti-human $A R$ antibody (clone AR441, DAKO, dilution of 1:100); mouse monoclonal Elk-1 antibody (clone sc-365876, Santa Cruz, dilution 1:100), and secondary antibody (Starr Trek Universal Link, Biocare Medical). Positive controls were benign lesions of prostate and normal ovarian tissue. Nuclear and cytoplasmic staining for AR and Elk-1 was semi-quantitatively evaluated. Percentage of positive cell was scored into $0,1,2$, $3,4(0,1=<10 \%, 2=10-50 \%, 3=51-80 \%$, and $4=>80 \%)$ and staining intensity was scored 0,1 , 2, 3 (0 = negative, 1 = weak, 2 = intermediate, and 3 = strong). Percentage and intensity scores were multiplied to generate an immunoreactive score ranging from 0 to 12 . The interpretation was $0-1=$ negative, 2-3 = mild, $4-8=$ moderate, and $9-12=$ strong. $A$ cutoff value of 4 was used to categorized AR and Elk-1 expression into negative and positive. AR and ELK-1 expression was scored by pathology with clinical data blinded. Statistical analysis for quantitative variables was a mean and standard deviation. Frequency and percentage were evaluated for qualitative variables. Fisher and Chi-square test was applied to determine correlation. $p<0.05$ was taken as significant.

\section{Results}

The mean age of patients was $70.68 \pm$ 7.99 years. The most prostate cancer cases were Gleason score $9(44.64 \%)$ and then Gleason score 8 (28.57\%) (Figure 1), histopathological grading poorly differentiated/undifferentiated $(76.78 \%)$ and WHO grade Group 5 (48.21\%).

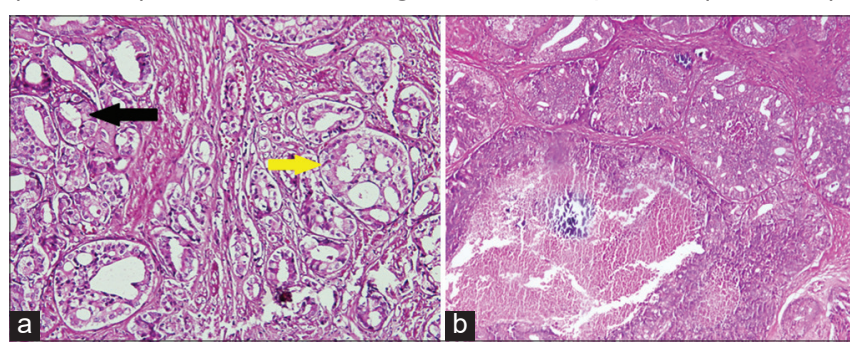

Figure 1: Gleason system based on International Society of Urological Pathology 2014/WHO 2016, (a) Gleason score 8 with fusion (black arrow) and cribriform pattern (yellow arrow), (b) Gleason score 9 with comedo necrosis (Hematoxylin and eosin, 200×)

Positive AR expression (Figure 2) was noted in $69.64 \%$ (39 cases) and positive Elk-1 expression (Figure 3) was seen in $60.71 \%$ (34 cases) as shown in Table 1.

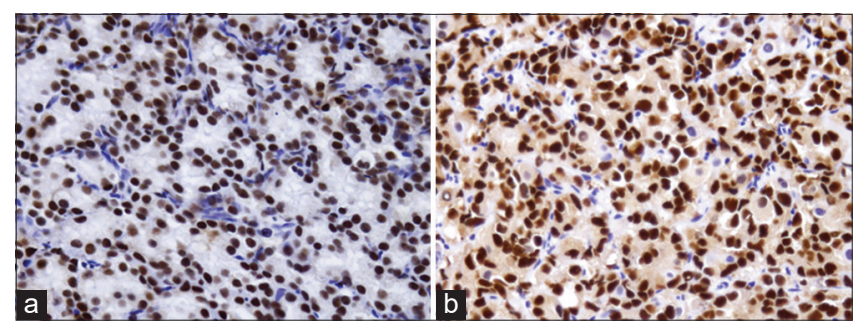

Figure 2: Androgen receptor expression of prostate cancer, (a) nuclear expression, (b) nuclear and cytoplasmic expression (400×)

Prostate cancer with a high-grade Gleason score showed more positive AR expressions (87.18\%), while low-grade Gleason scores $12.82 \%$. Statistically, the Fisher test showed a significant correlation between AR expression and Gleason score ( $p=0.009)$ (Table 2). High-grade Gleason score found more positive Elk-1 expressions (88.24\%), while low-grade Gleason

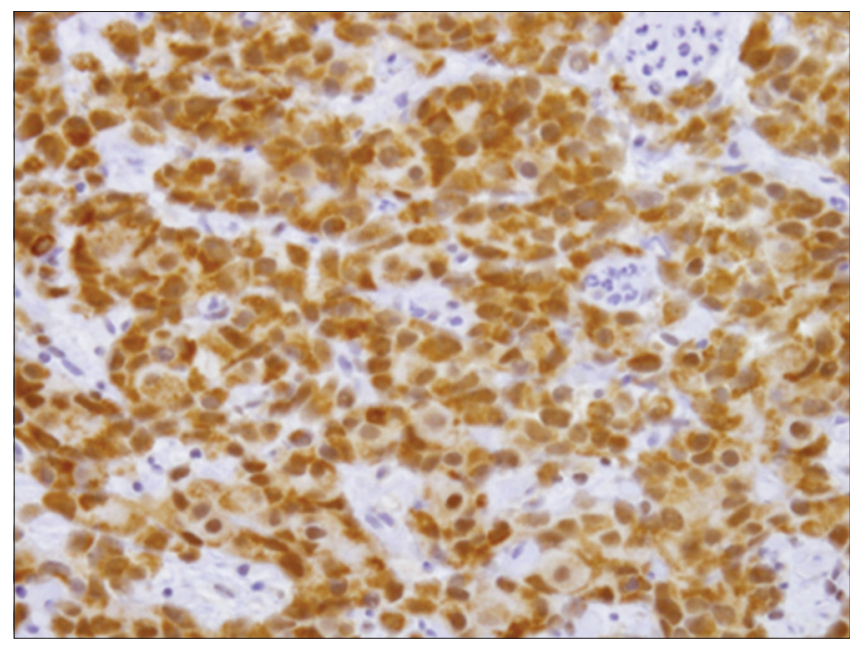

Figure 3: ETS-like protein1 expression of prostate cancer in nuclear and cytoplasmic (400x) 
scores $11.76 \%$. Chi-square test showed a significant correlation between Elk-1 expression with Gleason score $(p=0.012)$ (Table 3).

Table 1: The subject characteristics of study

\begin{tabular}{lll}
\hline Characteristics & $\mathrm{F}(\mathrm{n}=56)$ & $\%$ \\
\hline Age (years) & $70.68 \pm 7.99$ & \\
$\quad$ Mean \pm SD & 1 & 1.79 \\
Gleason score & 12 & 21.43 \\
6 & 16 & 28.57 \\
7 & 25 & 44.64 \\
8 & 2 & 3.57 \\
9 & 1 & \\
10 & 12 & 1.79 \\
Histopathological grading & 43 & 21.43 \\
$\quad$ Well diff (GS S6) & & 76.78 \\
Moderately diff (GS 7) & 1 & 1.79 \\
Poorly diff/undiff (GS 8-10) & 8 & 14.29 \\
WHO grade group & 4 & 7.14 \\
$\quad$ Grade 1 & 16 & 28.57 \\
Grade 2 & 27 & 48.21 \\
Grade 3 & & \\
$\quad$ Grade 4 & 17 & 30.36 \\
$\quad$ Grade 5 & 39 & 69.64 \\
AR expression & & 39.29 \\
Negative & 22 & 60.71 \\
$\quad$ Positive & 34 & \\
Elk-1 expression & & \\
$\quad$ Negative & &
\end{tabular}

\section{Discussion}

$A R$, the biomarker which is important in many human cancer especially genital tract, including prostate cancer. One of the studies stated that the most positive AR expression (95\%) was reported in prostate cancer rather than other urogenital cancer, with sensitivity $94.8 \%$, specificity $81.4 \%$, and $73 \%$ strongly positive [13].

Table 2: Correlation between AR expression with Gleason score

\begin{tabular}{|c|c|c|c|c|}
\hline \multirow[t]{2}{*}{ AR expression } & \multicolumn{2}{|l|}{ Gleason score } & \multirow[t]{2}{*}{ Total f (\%) } & \multirow[t]{2}{*}{$p$-value } \\
\hline & Low grade $\mathrm{f}(\%)$ & High grade $\mathrm{f}(\%)$ & & \\
\hline Negative & $8(47.06)$ & $9(52.94)$ & $17(100)$ & 0.009 \\
\hline Positive & $5(12.82)$ & $34(87.18)$ & $39(100)$ & \\
\hline Total & $13(23.21)$ & $43(76.79)$ & $56(100)$ & \\
\hline
\end{tabular}

Our study found AR-positive expressions in 69.64\% of prostate cancer cases. This result similar to Hashmi et al. that reported the most prostate cancer with high AR expression in $56.2 \%$ (68 cases) [14], as well as Lekshmy and Prema, reported AR expression in almost all prostate cancer cases [15].

Table 3: Correlation between Elk-1 expression with Gleason score

\begin{tabular}{lllll}
\hline Elk-1 expression & Gleason score & & Total f $(\%)$ & p-value \\
\cline { 2 - 3 } & Low grade $\mathrm{f}(\%)$ & High grade $\mathrm{f}(\%)$ & & \\
\hline Negative & $9(40.91)$ & $13(59.09)$ & $22(100)$ & 0.012 \\
Positive & $4(11.76)$ & $30(88.24)$ & $34(100)$ & \\
Total & $13(23.21)$ & $43(76.79)$ & $56(100)$ & \\
\hline Elk-1: ETS-like protein1. & & & &
\end{tabular}

AR signaling pathway is very important in the initiation and progression of prostate cancer. High AR expression is a significantly prognostic factor for prostate cancer in many studies. A few studies reported high AR expression as the result of gene amplification. It caused a lost of growth control with activated tumor cells more sensitive to the androgen castration level of the prostate. Besides, high AR expression can also increase response to ADT so that increasing survival rate [14], [15], [16].

The higher proliferation and progression of tumor cells, the worse differentiation grading based on histopathology. High proliferation and progression indicate poor biological behavior, affect histopathologic as the worse prognostic at the end. The study found that high-grade Gleason score (Gleason score 8-10) had more positive AR expression in tumor cells rather than a low grade (Gleason score 2-7). There is a significant correlation between AR expression and Gleason score $(p=0.009)$. Hashmi et al. also found a significant correlation between AR expression and Gleason score in tumor cells. Gleason score and grade group are the crucial marker in determining the progression of prostate cancer. This shows that high AR expression correlates with progression of prostate cancer [14]. The study by Chen et al. reported a significant correlation high AR expression with bone metastases of prostate cancer cases rather than without metastases $(p<0.001)$ [17]. Therefore, AR expression examination can be used as a prognostic predictor for prostate cancer [14]. However, some studies reported different results as Park et al. [16] and Husain et al. [18] which found a statistically insignificant correlation with Gleason score. High AR expression correlates with well-differentiated tumor cells (low-grade Gleason score). Loss or low AR expression in some tumor cells may be caused by several things as loss of $\mathrm{X}$-chromosome or epigenetic gene silencing [14]. This variation of results may also be caused by heterogeneous AR expression in prostate cancer cells, the difference in antibodies used to detect $A R$ receptors, and the difference in counting positively tumor cells [15].

Most of the positive AR expression of tumor cells showed in nuclear, some of them in nuclear and cytoplasmic of tumor cells. Many studies of prostate cancer evaluate positive AR expression in nuclear tumor cells only. Diallo et al. reported that positive cytoplasmic AR expression was higher in androgen/ligand-independent $A R$ and markedly more than in hormone-sensitive prostate cancer, but AR expression both in nuclear and cytoplasmic was significantly greater in hormone-sensitive rather than androgen/ligand-independent AR of prostate cancer. It is suspected that ADT might lead to increased cytoplasmic $A R$ and decreased nuclear AR so that cytoplasmic AR fluctuates much more than nuclear $A R$ in response to $A D T$. The remarkable increase in cytoplasmic AR could have results on the androgen/ ligand-independent AR phenotype. Umerous potential AR binding partners that either particularly remains in the cytoplasm or shuttle between the nucleus and cytoplasm have also been implicated in the progression of prostate cancer, including epidermal growth factor (EGF) receptor, Akt and NF-kB [19]. Other literature explains that ADT induces Src in non-DNA-binding AR 
signal pathway depends on androgen concentration. The pathway will be activated at low to physiological androgen level (0.1-10 nM) and inhibited by higher level (1-100 nM). This mirrors the biphasic effect of androgen, where low levels of androgens promote and high levels of androgens inhibit the growth of prostate cancer. Aberrant Src activity is presumably dependent on increased Src stimulation by growth factors and interleukins (IL) abundant in the tumor microenvironment, including EGF, insulin-like growth factor, IL-6, and IL-8 [9].

Positive expression Ek-1 in cytoplasmic and nuclear of tumor cells found $60.71 \%$, while negative expression $39.29 \%$. Kawahara et al. reported phospho-Elk-1 (p-Elk-1) predominantly in cytoplasmic tumor cells more than a high-grade PIN $(91.8 \%)$ and benign (64.7\%) [20]. Literature review about oncogenic transcription factor ETS family in solid tumor stated that overexpression Elk-1 of prostate cancer [21]. Elk-1 is a downstream effector of the MAPK/ERK signaling pathway and belongs to the ternary complex factor (TCF) subfamily of the ETS family transcription factors. Phosphorylation of Elk-1 through MAPK/ERK signaling pathways activate TCF with serum response factor (SRF) and serum response elements to induce target gene transcription. Various studies showed that prostate cancer was influenced by Elk-1, before and after castration therapy [22], [23], [24]. The study of Patki et al. reported that cooperative action of Elk-1 and AR did not involve phosphorylation of Elk-1, did not require $S R F$, and did not activate TCF. Instead, Elk-1 enabled sustained activation by AR of a distinct set of primarily cell growth-supporting genes. It is indicated that the underlying mechanism for the synergy between Elk-1 and AR is the recruitment of AR to the target genes as co-activator by Elk-1 [22].

The study found that statistically significant correlation between Elk-1 expression and Gleason score $(p=0.012)$. Most of the positive Elk-1 expression was high-grade Gleason score $(88.2 \%)$ rather than low grade $(11.8 \%)$. Pardy et al. reported a significant correlation between Elk-1 and Gleason score. Elk-1 was an independent risk factor for recurrence of prostate cancer along with clinical T-stage and prognostic grade. It warrants further detailed studies of the clinical utility of including Elk-1 with the currently used predictive signature of disease recurrence in prostate cancer [24]. Kawahara et al. found the different result that no statistically significant correlation between $p$-Elk-1 expression and tumor grade $(p=0.810)$, but there was a trend toward significance between moderate-strong p-Elk-1 expression and worse patients outcomes [20]. Most the studies demonstrated that Elk-1 was activated in prostate cancer and support the growth of tumor. Elk-1 also plays important roles in AR activation. Positive Elk-1 expressions were also found in most of the positive $A R$ expression in this study. Following the results of other studies have been published previously regarding the correlation Elk-1 with $A R$.

\section{Conclusion}

The results support previous studies that showed complex interactions between AR and Elk-1 in the initiation and progression of prostate cancer. All variables indicated a significant correlation with Gleason score so that biomarkers prognostic potentially for prostate cancer.

\section{References}

1. National Cancer Management Committee, Health Ministry of Indonesia. National Guidelines for Prostate Cancer Medical Services. Jakarta: National Cancer Management Committee; 2017. p. 1-13.

2. Bray F, Ferlay J, Soerjomataram I, Siegel RL, Torre LA Jemal A. Global cancer statistic 2018: GLOBOCAN estimates of incidence and mortality worldwide for 36 cancers in 185 countries. CA Cancer J Clin. 2018;68(6):394-424. https://doi. org/10.3322/caac.21492

PMid:30207593

3. Ferlay J, Soerjomataram I, Dikshit R, Eser S, Mathers C Rebelo $\mathrm{M}$, et al. Cancer incidence and mortality worldwide: Source, method and major pattern in GLOBOCAN 2012. Int J Cancer. 2015;136(5):359-86. https://doi.org/10.1002/ijc.29210 PMid:25220842

4. Cancer Registration Agency of the Indonesian Pathology Association. Directorate General of Medical Services Health Ministry of Indonesia. Cancer in Indonesia 2014 Histopathology Data. Jakarta: Cancer Registration Agency of the Indonesian Pathology Association; 2018.

5. Felgueiras J, Silva JV, Fardilha M. Prostate cancer: The need for biomarkers and new therapeutic targets. J Zheijiang Univ Sci B. 2014;15(1):16-42. https://doi.org/10.1631/jzus.b1300106 PMid:24390742

6. Ferraldeschi R, Welti J, Luo J, Attard G, Bono JS. Targeting the androgen receptor pathway in castration-resistant prostate cancer: Progresses and prospect. Oncogene. 2015;34()14:174557. https://doi.org/10.1038/onc.2014.115 PMid:24837363

7. Sun $Y$, Liu WZ, Liu T, Feng $X$, Yang N, Zhou HF. Signaling pathway of MAPK/ERK in cell proliferation, differentiation, migration, senescence and apoptosis. J Recept Signal Transduct Res. 2015;35(6):600-4. https://doi.org/10.3109/1079 9893.2015.1030412

PMid:26096166

8. Casalvieri KA, Matheson CJ, Bacos DS, Reigan P. Selective targeting of RSK isoform in cancer. Trends Cancer. 2017;3(4):302-12. https://doi.org/10.1016/j.trecan.2017.03.004 PMid:28718440

9. Leung Jk, Sadar MD. Non-genomic actions of the androgen receptor in prostate cancer. Front Endocrinol. 2017;8:1-8. https://doi.org/10.3389/fendo.2017.00002 
PMid:28144231

10. Epstein JI, Egevad LL, Amin MB, Delahunt B, Srigley JR, Humphrey PA. The 2014 International Society of Urological Pathology (ISUP) consensus conference on Gleason grading of prostatic carcinoma. AM J Surg Pathol. 2016;40(2):244-52. https://doi.org/10.1097/pas.0000000000000530

PMid:26492179

11. Humphrey PA, Epstein JI, Netto GJ, Amin MB, Egevad L, Rubin MA, et al. Acinar adenocarcinoma. In: Moch $\mathrm{H}$, Humphrey PA, Ulbright TM, Reuter VE, editors. WHO Classification of Tumours of the Urinary System and Male Genital Organs. 4th ed. Lyon: IARC Press; 2016. p. 138-61.

12. Shah RB, Zhou M. Recent advances in prostate cancer pathology: Gleason grading and beyond. Pathol Int. 2016;66(5):260-72. https://doi.org/10.1111/pin.1239 PMid:26991008

13. Williams EM, Higgins JP, Sangoi AR, McKenney JK, Troxell ML. Androgen receptor immunohistochemistry in genitourinary neoplasm. Int Urol Nephrol. 2015;47(1):81-5. https://doi.org/10.1007/s11255-014-0834-7

PMid:25218615

14. Hashmi AA, Mudassir G, Irfan M, Hussain ZF, Hashmi SK, Asif $\mathrm{H}$, et al. Prognostic significance of high androgen receptor expression in prostatic acinar adenocarcinoma. Asian Pac J Cancer Prev. 2019;20(3):893-6. https://doi.org/10.31557/ apjcp.2019.20.3.893

PMid:30912411

15. Lekshmy KS, Prema NS. Study of various prognostic factors in prostate cancer and its correlation with androgen receptor expression. J Evolution Med Dent Sci. 2019;8(34):2687-93.

16. Park SW, Kim JH, Lee HJ, Shin DH, Lee SD, Yoon S. The expression of androgen receptor and its variants in human prostate cancer tissue according to disease status, and its prognostic significance. World J Mens Health. 2019;37(1):6877. https://doi.org/10.5534/wjmh.180003 PMid:29756415

17. Chen $Y$, Lin $Y$, Nie $P$, Jiang $W$, Liu $Y$, Yuan $R$, et al. Association of prostate-specific antigen, prostate carcinoma tissue Gleason score, and androgen receptor expression with bone metastasis in patients with prostate carcinoma. Med Sci Monit.
2017;23:1768-74. https://doi.org/10.12659/msm.900977 PMid:28400549

18. Husain I, Shukla S, Soni P, Husain N. Role of androgen receptor in prostatic neoplasia versus hyperplasia. J Can Res Ther. 2016;12(1):112-6. https://doi.org/10.4103/0973-1482.151429 PMid:27072221

19. Diallo JS, Aldejmah A, Mouhim AF, Fahmy MA, Koumakpayi IH, Sircar K, et al. Co-assesment of cytoplasmic and nuclear androgen receptor location in prostate specimens: potential implication for prostate cancer development and prognosis. BJU Int. 2008;101(10):1302-9. https://doi. org/10.1111/j.1464-410x.2008.07514.x PMid:18294307

20. Kawahara T, Aljarah AK, Shareef HK, Inoue S, Ide H, Patterson JD, et al. Silodosin inhibits prostate cancer cell growth via Elk-1 inactivation and enhances the cytotoxic activity of gemcitabine. Prostate. 2016;76(8):744-56. https://doi. org/10.1002/pros.23164

PMid:26864615

21. Sizemore GM, Pitarresi JR, Balakrishnan S, Ostrowski MC The ETS family of oncogenic transcription factors in solid tumours. Cancer. 2017;17(6):337-351. https://doi.org/10.1038/ nrc. 2017.20

PMid:28450705

22. Patki M, Chari V, Sivakumaran S, Gonit M, Trumbly R, Ratnam M. The ETS domain transcription factor Elk1 directs a critical component of growth signaling by the androgen receptor in prostate cancer cells. J Biol Chem. 2013;288(16):11047-65. https://doi.org/10.1074/jbc.m112.438473 PMid:23426362

23. Hsing $M$, Wang $Y$, Rennie PS, Cox ME, Cherkasov A. ETS transcription factors as emerging drug targets in cancer. Med Res Rev. 2019;31(42):1904209. https://doi.org/10.1002/ med.21575

24. Pardy L, Rosati R, Soave C, Huang Y, Kim S, Ratnam M. The ternary complex factor protein Elk1 is an independent prognosticator of disease recurrence in prostate cancer. Prostate. 2020;80(2):198-208. https://doi.org/10.1002/ pros.23932

PMid:31794091 